\title{
EAl Endorsed Transactions

\section{Consideration of partial discharge energy in a mathematical model of thermal-fluctuation processes of a power cable}

\author{
M.N. Dubyago ${ }^{1}$, N.K. Polyuyanovich ${ }^{1, *}$, D.V. Burkov ${ }^{1}$ \\ ${ }^{1}$ Institute of Radio Engineering Systems and Control, Southern Federal University, Russian Federation.w_m88@mail.ru, \\ nik1-58@mail.ru, bdv-76@yandex.ru
}

\begin{abstract}
The article shows that the presence of impurities or oxidation products resulting from heating in insulation leads to leakage currents. A mathematical model was obtained that allows calculating the power of partial discharges (PD), as well as determining the location of the $\mathrm{m} 1$ inclusion in the main insulation, due to the power of the active component of the leakage current, when it occurs in the main cable insulation. The calculation of the change in heat flux passing through the layers of cable insulation by the piecewise-specified functions method, taking into account the thermal resistance of the inclusion, is carried out. The method proposed in the developed model makes it possible to account for heat losses based on the thermal and geometric dimensions of the inclusion. This will allow to obtain the temperature in all layers of the PCL, starting from the radial distances, inclusion parameters caused by the insulation core current, as the main temperature-forming factor.
\end{abstract}

Keywords: partial discharge energy, thermal fluctuation processes, insulation materials, power cables.

Received on 11 April 2019, accepted on 23 September 2019, published on 24 September 2019

Copyright (C) 2019 M.N. Dubyago et al., licensed to EAI. This is an open access article distributed under the terms of the Creative Commons Attribution licence (http://creativecommons.org/licenses/by/3.0/), which permits unlimited use, distribution and reproduction in any medium so long as the original work is properly cited.

doi: 10.4108/eai.13-7-2018.160391

*Corresponding author. Email:nik1-58@mail.ru

\section{Analytical review of publications and problem statement}

The capacity of power cable power supply systems is determined by its thermal conditions and is the defining characteristic. Temperature is one of the main factors causing insulation deterioration $[1,2,3]$. At the design stage of the PCL, according to the method described in IEC 60287, their throughput is determined, taking into account all possible factors arising during operation - they choose factors that provide a heating margin, therefore, in some cases, the cables are underloaded, and sometimes they work at the limit thermal stability. Numerous cases of failure of the power cable - as an essential element of the power supply system, due to exceeding the permissible temperature make the analysis of its thermal conditions very important.

In accordance with the general ideas about the destruction of insulation, the determining energy should be either the energy of a single partial discharge (PD) $\mathrm{W}_{\mathrm{PD}}$, or the power of discharges and PSD. In insulation, thermal breakdown may develop [4] associated with the heating of the dielectric when conduction current flows and the development of dielectric losses [5, 6,7]. However, direct measurement of $\mathrm{P}_{\mathrm{PD}}$ and $\mathrm{W}_{\mathrm{PD}}$ is in most cases practically impossible, since they are very small [8]. The amount of heat released in the dielectric is proportional to the dielectric loss. To measure the temperature of the most heated point of the cable (core), 
where the most intense thermal wear of the insulation occurs, is possible only by an indirect method. Therefore, an important task is research in the field of indirect temperature measurement based on a mathematical model of thermal processes that can be used in software algorithms for continuous diagnostics of power cables [9, 10]. The thermal field for PCL, the construction of which is shown in Fig. 2, is described by the differential heat conduction equation (1), which determines the change in temperature distribution in a volume as a function of time.

$$
\frac{\partial T}{\partial t}=\operatorname{div}(X \cdot \operatorname{grad}(T))+\frac{q_{D}}{c_{V}}
$$

where $q_{\mathrm{v}}$ - power of bulk heat sources (volumetric heat release density), $\mathrm{W} / \mathrm{M}^{3} ; \mathrm{T}$ - temperature, ${ }^{\circ} \mathrm{K} ; \mathrm{t}-$ time, $\mathrm{s} ; \mathrm{c}_{\mathrm{V}}$ - bulk heat capacity $\mathrm{J} /\left(\mathrm{K} \cdot \mathrm{m}^{3}\right) ; \chi$ - thermal conductivity, $\mathrm{m}^{2} / \mathrm{s}$. The coefficient $\chi \mathrm{s}$ determined by the formula $\chi=\lambda / c_{\mathrm{v}}$, where $\lambda-$ coefficient of thermal diffusivity, $\mathrm{W} /(\mathrm{m} \cdot \mathrm{K})$.

The methodologies for evaluating thermal steady-state SCR regimes described in IEC 60287 (1989) are based on the Neier-Mac Graf model, which boils down to determining the allowable load current of cables

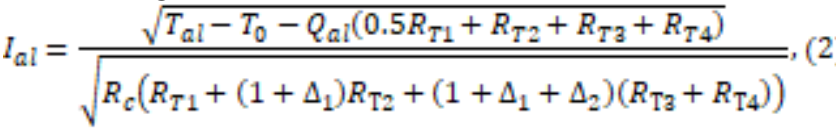

where $\mathrm{Q}_{\mathrm{al}}$ - dielectric loss in insulation per unit length, $\mathrm{T}_{\mathrm{al}}$ - permissible cable operating temperature (for XLPE insulation $-90^{\circ} \mathrm{C}$ ), ${ }^{\circ} \mathrm{C} ; \mathrm{T}_{0}-$ ambient temperature, ${ }^{\circ} \mathrm{C}$; $\mathrm{W} / \mathrm{m} ; \mathrm{R}_{\mathrm{c}}$ - electrical resistance of the core to alternating current per unit length at maximum operating temperature, $\Omega / \mathrm{m} ; \mathrm{R}_{\mathrm{T} 1}, \mathrm{R}_{\mathrm{T} 2}, \mathrm{R}_{\mathrm{T} 3}, \mathrm{R}_{\mathrm{T} 4}$ - thermal resistances of various layers of cable construction and environment per unit length, ${ }^{\circ} \mathrm{K} \cdot \mathrm{m} / \mathrm{W} ; \Delta_{1}, \Delta_{2}$ - the ratio of total losses in the screen and armor to the sum of losses in the conductive core.

In papers [4], on the contrary, IEC 60287 is used to determine the values of internal heat sources, and with the help of field models they calculate the temperature of cables.

The main regulatory document establishing the calculation of thermal processes in power cables is IEC 60287. Its identical variants are available in Russian GOST.

GOST 60287-1-1 considers the method of calculating the rated current load of the power cable based on the allowable temperature of the core. GOST 60287-1-3 proposes a method for calculating losses in metal sheaths of cables due to currents circulating in these sheaths, based on matrix methods.

In [11], the dependence of the specific thermal resistance and specific heat capacity on temperature for cross-linked polyethylene is analyzed. It is argued that this dependence is significant and must be taken into account in the calculations of the thermal processes of cables. Experimental graphs of these dependencies are given, as well as approximation relations.
In [11], a system of quasilinear parabolic differential equations is considered, which describes thermal processes in a single-core single cable laid in the air and the corresponding boundary conditions. The solution of this system with the substitution of the approximating dependencies from [11] is given. Experimental and theoretical diagrams of non-stationary thermal processes for the APVP cable are also shown, showing that the methodology is sufficiently adequate.

In [12], a method for calculating the thermal fields of a power cable is considered on the basis of solving a coupled problem of electrodynamics and heat transfer for cables made of cross-linked polyethylene using the equation of a plane-parallel quasistationary field. Given the calculated pattern of thermal fields, taking into account the currents in the cable screen.

Zaitseva ES, et al. [13] developed a mathematical model of temperature distribution in a high-voltage shielded cable with insulation made of cross-linked polyethylene, which allows analysis, knowing only its thermal characteristics and environmental conditions.

\section{The relevance of research}

The review of literature sources in the field of research of thermal-fluctuation processes based on thermal equivalent circuits of the PCL showed that when developing mathematical models for analyzing active losses affecting the state of the main cable insulation, electrodynamic forces of the lived and its own electromagnetic field were taken into account, leading to insulation heating, and as a result occurrence of leakage currents [14]. It was shown that despite the significant difference in operating modes, their combined effect on cable insulation occurs [14, 15]. However, none of the considered mathematical models takes into account the thermal losses caused by the PD in PCL insulation and their influence on the temperature distribution profile at characteristic points of the PCL cross section.

In this regard, the topic of partial discharges is a complex problem in electrical insulation, and the task of studying the effect on the isothermal characteristics of the PCL, the temperature gradient of inclusions in the main insulation, is important and relevant. We set the task of developing a mathematical model of the thermal processes of a power cable, taking into account the magnitudes of internal heat sources.

Heat processes in the PCL are caused by active losses (Fig. 1) which are converted into heat flux passing from the cores through the dielectric to the external environment $[16,17]$.

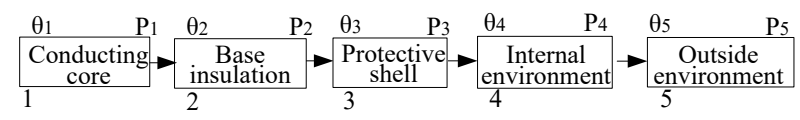

Figure 1. Structural diagram of thermal processes 
Power electrical losses in the conductors of the cable is determined by the known formula:

$$
\mathrm{P}_{\text {el }}=I^{2} R
$$

Active power is converted to heat flow [11]:

$$
Q=\lambda \frac{\Delta T}{\Delta \pi} S t
$$

The change in heat flux passing through the layers of cable insulation per unit of time is also an active power and is measured in [W]:

$$
P_{Q}=\frac{d Q}{d t}
$$

here $Q$ is the amount of heat transmitted through a layer of material with a thickness $A L$ of area $S$ while maintaining on its planes the difference in temperature $A T$ at a time $t, X$ is the specific thermal conductivity of the material.

The processes of insulation destruction under the action of heat flux are studied in detail, for example, in [18]. The presence in technical dielectrics of a small number of free charges associated with the presence of impurities or oxidation products resulting from heating in insulation leads to leakage currents, generally defined by equality [19-21]:

$$
I_{y}=U_{\omega C}
$$

where $U$ is the voltage between the dielectric layers; $\omega$ is the angular frequency of the current; C - capacitance between dielectric layers.

The calculation of the change in heat flux passing through the layers of cable insulation is carried out depending on the radial distances using the piecewisespecified functions method, which takes into account the location of the BI defect (m1). It depends on the degree of heating of the core and the thermal properties of the BI. Radial distances are calculated from the center of the core, which makes it possible to obtain a picture of the distribution of the temperature gradient.

The power released by the active component of the leakage current can be calculated by the formula:

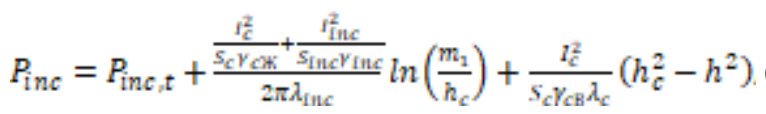

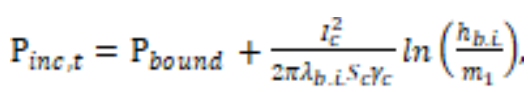

where $h$ is the radial distance (variable), $h_{c}$ is the radius of the outer edge of the main insulation, $\mathrm{m} 1$ is the location of the defect, $\mathrm{S}_{\text {Ж }}$ is the cross-sectional area of the core, $\delta_{\text {inc }}$ is the inclusion current density, $\mathrm{h}_{\mathrm{inc}}$ is the inclusion size, $\lambda_{\text {inc }}$ is the inclusion thermal conductivity, $\gamma_{\text {inc }}$ is the inclusion conductivity, $\gamma \mathrm{c}$ is the conductivity of the core, $\mathrm{h}$ (bi) is the outer radius of the main insulation, $\lambda$ (bi) is the thermal conductivity of the main insulation Pbound is the heat flux at the boundary of the inclusion and the main insulation:

Inclusion current density:

$$
\delta_{\text {ine }}=\frac{I y}{S_{\text {ine }}}=\frac{U \omega C_{\text {ine }}}{S_{\text {ine }}} .
$$

Inclusion capacity:

$$
C_{\text {ine }}=4 \pi \varepsilon_{0} \varepsilon_{\text {ine }} \frac{h_{\text {ine }}}{2}
$$

where $h_{\text {ine }}-$ inclusion height.

Thermal resistance of inclusion:

$$
R_{\text {ine }}=\frac{1}{\gamma_{\text {ine }}}=\frac{1}{q N_{U D}\left(\mu_{+}+\mu_{-}\right)^{x}}
$$

where $\gamma_{\text {ine }}-$ thermal conductivity; $N_{U D}-$ specific number of particles $\left(N_{U D}=2.6786 \mathrm{e}+25\right) ; \mu_{+} \mu_{-}-$mobility of positively and negatively charged particles.

Volume of the Inclusion:

$$
V_{\text {ine }}=\frac{4}{3} \pi\left(\frac{h_{\text {ine }}}{2}\right)^{3}
$$

The voltage on the inclusion of:

$$
\begin{aligned}
& U_{\text {ine }}=\varepsilon_{\mathrm{B}} \varepsilon_{0}\left(\frac{h_{\text {ine }}}{h}\right) \\
& h=h_{b \text {. i }}-h_{e^{x}}
\end{aligned}
$$

where $\mathrm{h}$ - radial distance of basic insulation.

The surface area of inclusion:

$S_{\text {ine }}=\frac{\pi h_{\text {ine }}^{2}}{4}$.

Charge of the inclusion:

$$
q=\frac{U \varepsilon_{0} \varepsilon_{\text {ine }} S_{\text {ine }}}{h_{\text {b.i. }}-h_{c}-h_{\text {ine }}} .
$$

To determine the location of the PD, the expression is entered into the system for calculating temperatures (7):

$$
m_{1}=h_{c}+\frac{I_{m}}{I_{E_{E}}}\left(h_{c}-h_{b i_{e}}\right)
$$

where $I_{n}-$ rated current of the conductor; $I_{t}-$ core current in real time.

Thus, the obtained mathematical model allows us to calculate the power of the partial discharge, as well as determine the $\mathrm{ml}$ (6) inclusion position in the main insulation, due to the power of the active component of the leakage current (7), when it occurs in the main cable insulation. 


\section{Materials and methods}

To monitor the thermal fluctuation processes in the PCL, the method of built-in temperature sensors is used [21, 22]. Consider a power cable as a system of the following thermal uniform bodies: conductive core, main insulation, screen, protective sheath, external cooling medium (Fig. 2).

a)

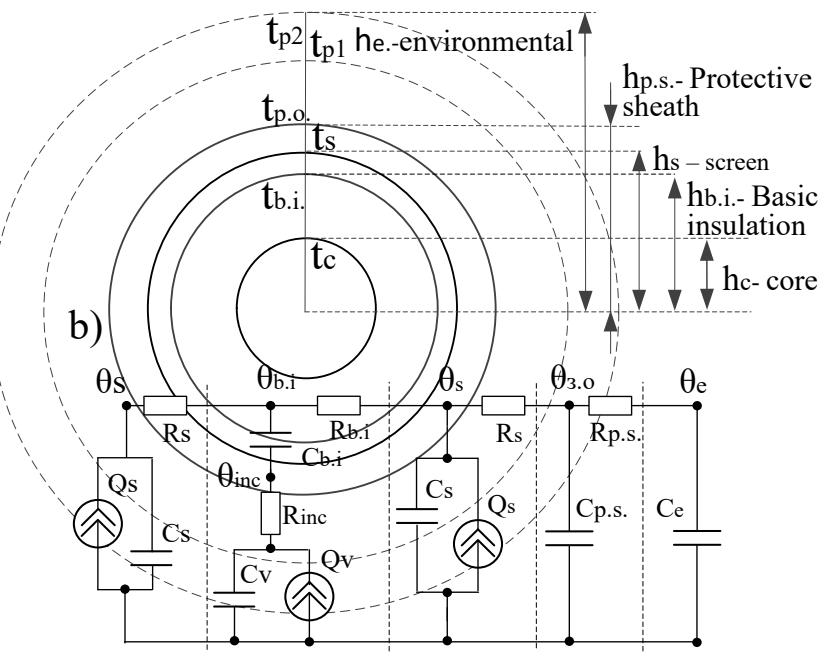

Figure 2. Cable cross-section and its thermal equivalent circuit

Where $\theta \mathrm{c}, \theta$ b.i., $\theta \mathrm{s}, \theta$ p.s, $\theta \mathrm{e}, \theta \mathrm{v}$ - temperatures respectively on conductive core, basic insulation of the core, the screen, protective sheath and the environment and the inclusion $\left({ }^{\circ} \mathrm{C}\right)$; Cc, Cs, Cb.i., Cp.s, C.e., $\mathrm{C}_{\text {inc }}$ are the heat capacities of the core, screen, main insulation, containment, environment and inclusion, respectively; Pc, Rs, Rb.i., Pp.s., Rv - thermal resistances respectively of conductive core, basic insulation of the core, the screen, protective cover and the inclusion; Qc, Qv, Qs - sources of current, replacing the temperature head, created by the current flowing through the core, the inclusion and the screen.

In $[14,23]$, the cable for calculating its thermal processes is considered as a system of homogeneous bodies (7).

$$
\begin{aligned}
& \left(\theta_{e}+\left(\frac{I_{c}^{2}}{\gamma_{c} c}+\frac{I_{s}^{2}}{\gamma_{s} S_{s}}\right) / 2 \pi r x_{\theta}\left(h=h_{e_{e}}\right)\right. \\
& \theta\left(h_{\theta_{0}}\right)+\ln \left(\frac{T_{e_{e}}}{h}\right)\left(\frac{I_{c}^{2}}{\gamma_{c} S_{e}}+\frac{I_{s}^{2}}{\gamma_{s} S_{s}}\right) / 2 \pi \lambda_{e} \\
& \left(h_{p, s_{0}} \leq h \leq h_{e_{0}}\right) \\
& \theta\left(h_{p s s}\right)+\ln \left(\frac{p_{p s}}{h}\right)\left(\frac{I_{c}^{2}}{\gamma_{c} S_{e}}+\frac{I_{c}^{2}}{\gamma_{c} S_{v}}\right) / 2 \pi \lambda_{b \hat{d}_{v} v} \\
& \left(h_{g} \leq h \leq h_{p, s .}\right) \\
& \theta\left(h_{g}\right)+\ln \left(\frac{h_{3}}{h}\right) \frac{\frac{l_{s}^{2}}{\gamma_{c} S_{e}}-\frac{j_{s}^{2}}{\gamma_{s}} h_{b .1}^{2} \pi}{2 \pi \lambda_{g}}+\frac{j_{s}^{2}\left(h_{s}^{2}-h^{2}\right)}{4 \lambda \gamma_{s}} . \\
& \left(h_{b, j_{0}} \leq h \leq h_{g}\right) \\
& \theta(h)=\left\{\begin{array}{c}
\left(h_{b, i_{0}} \leq h \leq h_{g}\right) \\
\theta\left(h_{b, i}\right)+\ln \left(\frac{h_{b, i}}{h}\right) \frac{\frac{l_{c}^{2}}{\gamma_{c} S_{c}}}{2 \pi \lambda_{b i}}+\frac{j_{b i j}^{2}\left(h_{b, i}^{2}-h^{2}\right)}{4 \lambda_{b i j} \gamma_{b, i}}{ }^{(7)}
\end{array}\right. \\
& \left(m_{1}+2 r_{V} \leq h \leq h_{b: i}\right) \\
& \theta\left(h_{\text {bound }}\right)+\frac{\frac{l_{c}^{2}}{\gamma_{c} S_{c}}+\frac{l_{\text {inc }}^{2}}{S_{\text {inc }} \gamma_{\text {ine }}}}{2 \pi \lambda_{\text {ine }}} \ln \left(\frac{m_{1}}{h_{c}}\right)+\frac{I_{\text {ine }}^{2}\left(h_{c}^{2}-h^{2}\right)}{S_{\text {ine }} \gamma_{\text {ine }} \lambda_{\text {ine }}}+ \\
& +\frac{l_{c}^{2}}{2 \pi \lambda_{b i} S_{c} y_{c}} \ln \left(\frac{h_{b \lambda_{i}}}{m_{1}}\right),\left(m_{1} \leq h \leq m_{1}+h_{\text {ine }}\right) \\
& \theta\left(h_{b, i}\right)+\ln \left(\frac{h_{b, i}}{h}\right) \frac{\frac{l_{s}^{2}}{\gamma_{c} S_{e}}}{2 \pi \lambda_{b, j}}+\frac{j_{b, i}^{2}\left(h_{b, i}^{2}-h^{2}\right)}{4 \lambda_{b i j} \gamma_{b, i}} . \\
& \left(h_{c} \leq h \leq m_{1}\right) \\
& \theta\left(h_{c}\right)+j_{c}^{2}\left(h_{c}^{2}-h^{2}\right) / 4 \lambda_{c} \gamma_{c}
\end{aligned}
$$

However, this model does not take into account such factors as the effect on the heating of the cable - dielectric losses in the insulation, namely the PD. The proposed mathematical model (7), along with the layer-by-layer calculation of isotherms in the cross-section of the cable (Fig. 3), makes it possible to determine the presence of inclusions in the insulating material. The heat released in the insulating material (dielectric) Qb.i is calculated and proportional to the dielectric losses in the inclusions (partial discharge energy WPD) is made by analogy with the calculation of the released heat Q in the core (screen) [14], but only taking into account the power released by the active component of the leakage current.

The temperature profile in the cross section of the investigated power cable APU Pu g-1x240 / 25-10 was determined by the system of equations (7), in accordance with the theory of thermal conductivity, Fig. 2, where $I_{c}$, $I_{s}-$ currents in the core and the screen; $x$ - coefficient of thermal conductivity $a=\lambda / c * \rho\left[\mathrm{m}^{2} / s\right] ; \quad j_{c}=I_{c} / S_{c}$; $j_{s}=I_{s} / S_{s} ; S_{c}, S_{s}-$ cross-sectional of the core and screen surface areas; $\gamma_{\mathrm{c}}, \gamma_{\mathrm{s}}$ - conductivity of the core and the screen, $\delta_{b, i}=I_{y} / S_{b i_{\mathrm{o}}}=U * w * C b . i / S b . i$.

\section{Results and discussions}


The physical properties of the materials and the geometrical dimensions of the elements of the cable APVPu g-1x240 / 25-10, are summarized in Table 1.

Table 1. Cable parameters.

\begin{tabular}{|c|c|c|c|c|}
\hline Parameter $\quad$ Material & Aluminum & XLPE & Copper & Air \\
\hline $\begin{array}{l}\text { Thermal conductivity } \\
(\mathrm{W} /(\mathrm{m} \cdot \mathrm{k}))\end{array}$ & 209.3 & 0.38 & 400 & $\begin{array}{c}0.02 \\
59 \\
\end{array}$ \\
\hline Density (kg/m3) & 2700 & 2200 & 8700 & 1.2 \\
\hline $\begin{array}{l}\text { Specific heat } \\
(\mathrm{J} /(\mathrm{kg} \cdot \mathrm{k}))\end{array}$ & 920 & 1900 & 385 & 1005 \\
\hline $\begin{array}{l}\text { Electrical conductivity } \\
(\mathrm{S} / \mathrm{m})\end{array}$ & $31,75^{*} 10^{6}$ & $1 \cdot 10^{-9}$ & $5 * 10^{7}$ & -- \\
\hline
\end{tabular}

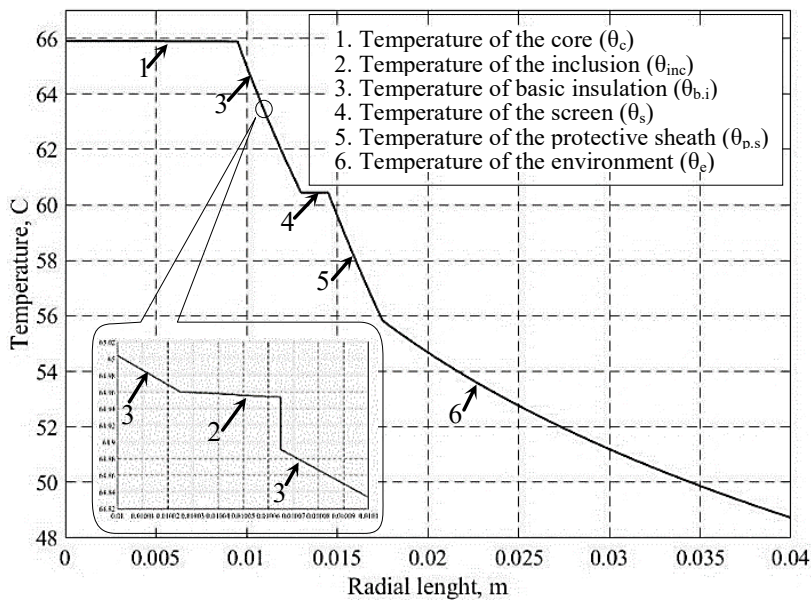

Figure 3. Graphs of the temperature distribution in the characteristic points of the cross section of $\mathrm{CL}$

In accordance with the system of equations (7) in Matlab, a temperature gradient is constructed in the cross section of the cable and the environment. The calculations were performed with a current in the cable core up to 640 , A. The current in the cable jacket is determined by the cable operation mode (core current), 60\% was adopted in relation to the core current.

Since the literature on the calculation of thermofluctuation processes, taking into account the size and location of the inclusion in the main insulation of the power cable, was not revealed by the authors, no comparison was made. However, in [21], a comparison was made between the experimental and calculated values of core temperatures for a given temperature on the cable surface, as well as a comparison with the model results [22], and high values of the correlation coefficient were shown.

\section{Conclusion}

Thus, the analysis of the obtained isothermal dependencies of highly heat-conducting elements (core and cable shield) shows their weak dependence on temperature change (horizontal shelves in the graph). The temperature gradient obtained in the insulating material (XLPE cable) confirms their insignificant heat conduction. The significant difference between the measured temperature ( $\theta$ p.s.) and the temperature at the cable core makes it necessary to recalculate the surface temperature of the cable ( $\theta$ p.s.) to the temperature of the core $(\theta \mathrm{c})$. That is, it is sufficient to determine the temperature field on the cable surface ( $\theta$ p.s.), and then, based on the system of heat conduction equations (7), obtain the temperature over all layers of the cable.

The study of the obtained temperature distribution profile showed the possibility of modeling along with the temperature field of the cable, losses in inclusions (partial discharge energy WPD). So from Figure 3, one can see the presence of inclusions in the insulating material, their number and location in the dielectric. This indicates the thermal deterioration of the insulation, due to the power (7) determined by the active component of the leakage current, and is observed near the cable core. In comparison with $[5,14]$, the proposed mathematical model takes into account the heat losses caused by PD in PCL insulation and their influence on the temperature distribution profile at characteristic PCL section points. The method proposed in the developed model makes it possible to account for heat losses based on the thermal and geometrical dimensions of the inclusion, which was not taken into account in the models mentioned above. This will allow to obtain the temperature in all PCL layers, starting from the radial distances, inclusion parameters caused by the insulation core current, as the main temperature-forming factor.

\section{References}

[1] Chen, J. Method of estimating the remaining life of the 10 $\mathrm{kV}$ XLPE cable operated 10 years / J. Chen, S. Wang // Proc. 6th Int. Conf. Prop. Appl. Dielectr. Mater. (Cat. No.00CH36347). - 2000. -Vol. 1. - C. 204-208

[2] Mazzanti, G. Analysis of the combined effects of load cycling, thermal transients, and electro-thermal stress on life expectancy of high-voltage AC cables / G. Mazzanti // IEEE Trans. Power Deliv. - 2007. - Vol. 22. - № 4. - pp. 2000-2009.

[3] Mazzanti, G. The combination of electro-thermal stress, load cycling and thermal transients and its effects on the life of high voltage AC cables / G. Mazzanti // IEEE Trans. Dielectr. Electr. Insul. -2009. - Vol. 16. - № 4. - pp. 1168 1179.

[4] Merkulov V.I. Mathematical modeling in electrical insulating structures [Text] / V.I. Merkulov // Textbook. Tomsk: Ed. TPU, $2001-156$ p.

[5] Kuchinsky, G.S. Isolation of high voltage installations [Text] / G.S. Kuchinsky // Energo-atomizdat, 1987. -367p.

[6] Langlois, V. Thermooxidative aging of crosslinked linear polyethylene: Stabilizer consumption and lifetime 
prediction / V. Langlois and etc. // Polym. Degrad. Stab. - 1993. - Vol.. 40. - № 3. - pp. 399-409.

[7] Sugimoto, M. Product analysis for polyethylene degradation by radiation and thermal ageing / M. Sugimoto and etc // Radiat. Phys. Chem. Elsevier. - 2013. - Vol.82. - № 1. - pp. 69-73.

[8] X. Ma, C. Zhou, I. J. Kemp. Interpretation of Wavelet Analysis and Its Application in Partial Discharge Detection. //IEEE Transactions on Dielectrics and Electrical Insulation. Vol. 9, №3, June 2002. -pp.446-457.

[9] Ouatah, E. Characteristics of partial discharge pulses propagation in shielded power cable / E. Ouatah and ets // Electr. Power Syst. Res. Elsevier B.V. - 2013. - Vol. 99. - pp. 38-44.

[10] He, X. Online partial discharge detection and location system using Wireless Sensor Network / X. He, G. Xie, Y. Jiang // Energy Procedia. - 2011. - Vol. 12. - pp. 420-428.

[11] Calculation of permissible loads of single-core cables with plastic insulation / E. T. Larina [et al.] // Electrotechnology. - 1991. - No. 3. - pp. 28-31.

[12] Titkov, V.V. On the assessment of the thermal regime of a three-phase line from an SPE cable / V.V. Titkov // Cablenews. - 2009. - No. 10. - pp. 47-51.

[13] Zaitsev E.S., Korolkov V.V., Lebedev V.D., Mozhzhukhina V.V. Simulation of thermal processes in cable with XLPE insulation Matlab and Simulink.

[14] Korzhov A.V., Tomasheva E.V. "The power diagram of the power cable for the analysis of active losses affecting the state of the insulation." Bulletin of SUSU, No. 11, 2008. Series "Energy", Issue 9. p.29-31

[15] Luo, P. Thermal and mechanical properties analysis for EHV XLPE cables with different operating years / P. Luo и др. // 2013 Annual Report Conference on Electrical Insulation and Dielectric Phenomena.- T.3. - C.47-51

[16] Deshpande, A.S. Partial discharge analysis using energy patterns / A.S. Deshpande, H.A. Mangalvedekar, A.N. Cheeran // Int. J. Electr. Power Energy Syst. - 2013. - Vol. 53. - pp. 184-195.

[17] Aras, F. Aging of $154 \mathrm{kV}$ underground power cable insulation under combined thermal and electrical stresses / F. Aras и др. // IEEE Electr. Insul. Mag. - 2007. - Vol. 23. - № 5. - pp. 25-33.

[18] Leonov V.M. Fundamentals of cable technology: a textbook for students. institutions of higher education. / V.M. Leonov, I.B. Peshkov, I.B. Ryazanov, S.D. Cold; under the editorship of I.B. Peshkova. - M.: Publishing Center "Academy", 2006. - 432 p.

[19] Koshkin N.I. Handbook of elementary physics / N.I. Koshkin, M.G. Shirkevich. - M .: Nauka, 1974.

[20] Shimada, A. Degradation distribution in insulation materials of cables by accelerated thermal and radiation ageing / A. Shimada и др. // IEEE Trans. Dielectr. Electr. Insul. - 2013. - T. 20. - № 6. - C. 2107-2116.

[21] Rotating electrical machines - Part 1: Rating and performance // IEC Revision of Publication 60034. - draft 1. - 2004. - 137 p.

[22] Ismagilov, F.R. A method for estimation of insulation residual operation capability of electrical equipment / F.R. Ismagilov, D.V. Maksudov // Russ. Electr. Eng. - 2012. T. 83. - № 2. - C. 118-120.

Neher, J.H. The Transient Temperature Rise of Buried Power Cable Systems /J.H. Neher // IEEE Transactions. 1964. - Vol. PAS-83. - P. 102-111 